\title{
O Sistema Único de Saúde como paradigma nas representaçóes sociais dos cirurgiões-dentistas
}

Sérgio Xavier de Camargo ${ }^{1}$

Luiza Nakama²

Luiz Cordoni Junior ${ }^{3}$

CAMARGO, S.X.; NAKAMA, L.; CORDONI JUNIOR, L. The Brazilian National Health System as a paradigm in dentists' social representations. Interface - Comunic., Saude, Educ., v.15, n.38, p.883-900, jul./set. 2011.

The purpose of this study was to investigate whether the Brazilian National Health System (SUS) is recognized by dentists as a paradigm for professional practices. This was a qualitative study that analyzed the social representations of SUS among these professionals. The study group was formed by dentists whose professional activity was connected with public healthcare services, specifically public servants and university teachers, consisting of three cases: traditional public service professionals in Londrina (Paraná); family healthcare strategy professionals in Curitiba (Paraná); and dentistry school lecturers in Londrina (Paraná). The results showed three possibilities: a lack of knowledge about SUS; knowledge and skepticism; and knowledge and Utopia. It was concluded that SUS is not completely recognized as a reference point for dental care among dentists, and that dentists' adherence to the SUS project was dependent on an association between knowledge of SUS and personal faith in its viability.

Keywords: Brazilian National Health System. Dentistry. Family health. Social representations. Human resources.
Este estudo se propôs a verificar se o Sistema Único de Saúde (SUS) é reconhecido pelos cirurgiões-dentistas como paradigma para a prática profissional. Trata-se de uma pesquisa qualitativa que analisou as representações sociais do SUS desses profissionais. $\mathrm{O}$ grupo de estudo reuniu dentistas com atuação profissional vinculada aos serviços públicos de Saúde, especificamente servidores públicos e professores universitários, sendo constituído por três casos: profissionais do serviço público tradicional de Londrina (PR); profissionais da Estratégia Saúde da Família (ESF) de Curitiba (PR); docentes de faculdades de Odontologia de Londrina (PR). Os resultados evidenciaram três possibilidades: desconhecimento do SUS; conhecimento e ceticismo; conhecimento e Utopia. Conclui-se que o SUS não é plenamente reconhecido como referencial para a atenção odontológica pelos cirurgiões-dentistas, e que sua adesão ao projeto SUS se dá apenas na contingência da associação entre conhecimento do SUS e crença pessoal em sua viabilidade.

Palavras-chave: Sistema Único de Saúde. Odontologia. Saúde da família.

Representações sociais. Recursos humanos.
1,3 Departamento de Saúde Coletiva, Centro de Ciências da Saúde, Universidade Estadual de Londrina (CCS/UEL). Avenida Robert Koch, 60. Vila Operária. Londrina, PR, Brasil. 86.039-440. sergioxc@uol.com.br

${ }^{2}$ Departamento de Medicina Oral e Odontologia Infantil, CCS, UEL. 


\section{Introdução}

A República Federativa do Brasil - configurada como Estado Social e Democrático de Direito, promotor de justiça social - tem, na garantia de atenção à Saúde, um de seus maiores desafios. Conta para tanto com o Sistema Único de Saúde (SUS), instituto legítimo e democrático de mais de vinte anos, advindo da Reforma Sanitária.

Conforme Junges (2009, p.285),

quando a maioria dos países do Primeiro Mundo iniciava um processo de desmonte do Estado de bem-estar social, seguindo a cartilha neoliberal, o Brasil apostou num sistema público de saúde fundado na universalidade e na equidade do acesso aos recursos necessários a uma saúde integral. Essa opção nacional foi fruto de um pacto construído, durante anos, com muita eficiência política e social pelo movimento sanitarista brasileiro.

Muitos autores têm analisado os avanços e impedimentos na efetivação do SUS como estratégia de consolidação da Reforma Sanitária, que objetiva, mais que garantir saúde, efetivar a transformação da realidade social, enquanto projeto emancipatório da sociedade (Cohn, 2009; Menicucci, 2009; Paim, 2009, 2008; Santos, 2009; Campos, 2008; Mendes, 1996, 1993).

O SUS, pretendendo garantir e efetivar direitos sociais, é construído em processo histórico resultante da ação de múltiplos vetores sociais, de interesses por vezes contraditórios, sendo, há muito, apresentado como um processo social em construção (Mendes, 1996).

Um dos principais vetores desse processo histórico é constituído pelos profissionais que nele atuam. Conhecer o referencial simbólico destes atores quanto ao SUS é fundamental para compreendê-lo em seu contexto presente, bem como em suas perspectivas futuras. Tais significados, socialmente produzidos pelos profissionais, podem ser compreendidos pelo estudo das Representações Sociais (RS), que se revelam sob a forma de "teorias" representativas da interpretação coletiva da realidade (Berger, Luckmann, 2002; Moscovici, 1981).

Segundo Moscovici (1978), a representação social é um conjunto organizado de figuras (que se constituíram em imagens) e de expressões socializadas (que se constituíram em linguagem) que realçam e simbolizam as situações e os atos. A representação produz comportamentos, visto que define a natureza dos estímulos que nos rodeiam e provocam; ao mesmo tempo, determina esses comportamentos, à proporção que define o significado das respostas a serem dadas aos estímulos.

Para se conhecer o papel dos profissionais no processo social de construção do SUS importa saber quais são suas RS em uma dimensão político-assistencial reveladora de ideologias que as sustentam. Tais RS devem ser confrontadas com paradigmas idealizados do SUS.

Especificamente quanto à Saúde Bucal, muitos autores (Frazão, 2009; Frazão, Narvai, 2009; Narvai, 2006; Roncalli, 2000; Cordón, 1998) têm discutido as necessidades e os anseios da população pelo exercício deste direito, bem como os grandes desafios relativos à sua efetiva realização.

De acordo com Nunes et al. (2008, p.413),

as práticas profissionais dos cirurgiões-dentistas que atuam nos serviços públicos de saúde refletem o modelo flexneriano de formação das diversas instituições de ensino brasileiras. Apesar do crescente aumento no número de faculdades de odontologia nas últimas décadas e das novas diretrizes curriculares, poucas mudanças podem ser observadas na formação de seus egressos.

Em face das mais de duas décadas de instituição jurídica do SUS, das dificuldades de sua implantação como Modelo de Atenção em Saúde no Brasil, e, em especial, relativamente à atenção odontológica no SUS, cogita-se que os significados das RS dos profissionais possam ser fatores associados a esta realidade. Como objetivo, o estudo propõe verificar se o SUS é reconhecido como paradigma válido pelo cirurgião-dentista para a prática profissional odontológica e, ainda, identificar e analisar estas RS do cirurgião-dentista sobre o SUS. 
${ }^{4} \mathrm{O}$ reconhecimento do Programa Saúde da Família (PSF) como Estratégia Saúde da Família (ESF) foi instituído pela Portaria $n^{\circ} 648$ /GM de 28 de março de 2006 (Brasil, 2007). Este trabalho utiliza a terminologia ESF, não obstante preserve a terminologia PSF quando referente às manifestações dos trabalhadores de saúde entrevistados, visto ser este o termo consagrado pelo uso em suas relações de comunicação intersubjetiva.

${ }^{5}$ De acordo com Triviños (1987), " podemos entender por entrevista semi-estruturada, em geral, aquela que parte de certos

questionamentos básicos, apoiados em teorias e hipóteses, que interessam à pesquisa, $\mathrm{e}$ que, em seguida, oferecem amplo campo de interrogativas, fruto de novas hipóteses que vão surgindo à medida que se recebem as respostas do informante. Desta maneira, o informante, seguindo espontaneamente a linha de seu pensamento e de suas experiências dentro do foco principal colocado pelo

investigador, começa a participar na elaboração do conteúdo da pesquisa" (Triviños, 1987, p.146).

${ }^{6}$ Conforme o autor, o Estudo Multicaso diferencia-se do Estudo Comparativo de Casos por propiciar a possibilidade de estudar dois ou mais sujeitos, organizações, sem a necessidade de perseguir objetivos de natureza comparativa.

\section{Procedimentos metodológicos}

O grupo de estudo foi constituído por 26 cirurgiões-dentistas com atuação profissional vinculada ao SUS, configurando três casos ou subgrupos de estudo: a) profissionais do serviço público tradicional; b) profissionais da Estratégia Saúde da Família (ESF) ; c) docentes de faculdades de Odontologia. Para a seleção da população de estudo, foi utilizada a estratégia de amostragem não probabilística, intencional. O subgrupo dos profissionais tradicionais foi constituído por oito dentistas da rede pública de Londrina, não inseridos na ESF, e o subgrupo dos profissionais da ESF, por oito dentistas da rede pública de Curitiba. Para ambos os subgrupos, foi estabelecido o critério de seleção dos profissionais por máxima variação ou heterogeneidade (Patton, 2002), com os quatro profissionais com maior tempo no serviço público e maior idade, e os com menor tempo de serviço público e de menor idade, a partir de informações fornecidas pelas secretarias municipais de saúde. O subgrupo dos docentes foi constituído de dez dos 16 professores universitários das disciplinas de Odontologia Social e Preventiva e de Odontopediatria, dos cursos de Odontologia da Universidade Estadual de Londrina (UEL), e da Universidade Norte do Paraná (UNOPAR), instituição privada, de Londrina.

No período de coleta de dados, o município de Curitiba já contava com ampla experiência da inserção da Odontologia na ESF, e o município de Londrina estava na iminência de iniciar esta inserção.

Foi usada a estratégia de seleção mista (Patton, 2002), com seleção por caso crítico para o grupo de estudo, e seleção por máxima variação, para os subgrupos de estudo. O caso crítico permite generalização dos resultados por inferência. A máxima variabilidade permite verificar a influência dos fatores idade e tempo de atuação no SUS, bem como propiciar maior amplitude e diversificação das RS.

Foram realizadas entrevistas com os profissionais, seguindo um roteiro semiestruturado ${ }^{5}$, entre junho e novembro de 2003, sendo proposta a questão: "Como você vê o SUS?".

Todas as entrevistas foram concedidas espontaneamente, após assinatura do Termo de Consentimento Livre e Esclarecido firmado entre entrevistados e entrevistador, além do Termo de Compromisso do pesquisador junto ao Comitê de Ética em Pesquisa, da Universidade Estadual de Londrina, no qual foi aprovada a pesquisa.

Os dados foram transcritos, processados com auxílio do programa de software NVivo, versão 1.2, e analisados pela técnica de Análise de Conteúdo Temática (Bardin, 2004).

Esta investigação, de natureza qualitativa, configurou-se um Estudo Multicaso ${ }^{6}$ (Triviños, 1987) e um Estudo de Caso Coletivo ${ }^{7}$ (Stake, 2000), e utilizou a análise temática das Representações Sociais como instrumento teórico-metodológico para pesquisar os significados e valores dos cirurgiões-dentistas, relativos ao SUS.

As RS são definidas por Moscovici (1981) como um conjunto de conceitos, proposições e explicações originado na vida cotidiana no curso de comunicações interpessoais, e equivalentes, em nossa sociedade, aos mitos e sistemas de crença das sociedades tradicionais, e à versão contemporânea do senso comum.

Minayo (2002) fundamenta o tema na sociologia clássica de Durkheim, Marx e Weber, entre outros. Segundo a autora, em Durkheim, as Representações Coletivas são categorias de pensamento com que as sociedades expressam sua realidade, a partir de fatos sociais. Em Marx, as representações, as ideias e os pensamentos são o conteúdo da consciência, determinada pela base material da vida real. Em Weber, as ideias (RS) são juízos de valor que os indivíduos dotados de vontade possuem, 
com autonomia frente à infraestrutura material. Em Schultz, as RS no cotidiano são o senso comum, construído e interpretado a partir do dia a dia.

Este estudo pressupõe, conforme Oliveira e Werba (2002), que RS sejam "teorias" sobre saberes populares e do senso comum, elaboradas e partilhadas coletivamente, com a finalidade de construir e interpretar o real.

Neste estudo, RS referentes ao SUS foram identificadas; estas RS foram tratadas como temas de análise pela técnica de análise de Conteúdo, modalidade Temática, seguindo metodologia de Bardin (2004). Como método de interpretação, na análise dos dados, preferiu-se a análise hermenêutico-dialética, conforme indica Minayo (2000), que a considera adequada às dimensões e dinâmicas das complexas relações que tenham a saúde como objeto de investigação.

Para Bardin (2004), a análise de conteúdo comporta diferentes fases: 1) a préanálise; 2) a exploração do material; 3) o tratamento dos resultados, a inferência e a interpretação.

Seguindo este referencial, o presente estudo realizou: a leitura flutuante, a escolha dos documentos e a constituição de um corpus (conjunto dos documentos a serem submetidos à análise), a formulação das hipóteses e dos objetivos, privilegiando os procedimentos exploratórios, e a preparação do material (material e formal).

Quanto ao tratamento dos resultados, foi escolhido o tema ${ }^{8}$ como unidade de análise.

Por fim, outras duas categorias fundamentais para a análise proposta são: a dimensão política e a dimensão ideológica destas representações.

A dimensão político-assistencial das representações é evidenciada por Paim (2002), ao apontar quatro tipos de concepções vigentes sobre o SUS: a) o SUS democrático, desenhado pelo projeto da Reforma Sanitária Brasileira; b) o SUS formal, juridicamente estabelecido pela Constituição Federal; c) o SUS real, refém dos desígnios da chamada área econômica do governo, do clientelismo e da inércia burocrática; d) o SUS-para-pobre, "um susto pobre para a doença do pobre, uma medicina simplificada para gente simples", mediante políticas de "focalização" (Paim, 2002, p.253).

A análise representacional do SUS em sua dimensão ideológica requer definição do termo "Ideologia". Mannheim (1968) faz distinção entre dois tipos de observação e enunciação falsos: uma concepção particular e uma concepção total de ideologia. Para o autor, a concepção particular, inclui

todas as expressões cuja falsidade é devida à ilusão de si mesmo ou de outros, intencional ou não, consciente, semiconsciente ou inconsciente, que ocorre em nível psicológico e se assemelha estruturalmente à mentira. Chamamos de particular a esta concepção de ideologia. [...] A Sociologia do Conhecimento, por outro lado, toma como seu problema exatamente esta estrutura mental em sua totalidade, tal qual ela aparece nas diferentes correntes do pensamento e dos grupos histórico-sociais. [...] Uma vez que a suspeita de falsificação não se inclui na concepção total de ideologia, o uso do termo "ideologia" na Sociologia do Conhecimento não possui intenção moral ou denunciadora. (Mannheim, 1968, p.287-8)
${ }^{7}$ Stake (2000) distingue três tipos de estudos de caso a partir de suas finalidades: intrínseco, instrumental e coletivo. No estudo de caso intrínseco, busca-se melhor compreensão de um caso apenas pelo interesse despertado por aquele caso particular. No estudo de caso instrumental, ao contrário, o interesse no caso deve-se à crença de que ele poderá facilitar a compreensão de algo mais amplo, uma vez que pode servir para fornecer insights sobre um assunto ou para generalização amplamente aceita, apresentando um caso que não se encaixa; no estudo de caso coletivo, o pesquisador estuda conjuntamente alguns casos para investigar um dado fenômeno,

podendo ser visto como um estudo instrumental estendido a vários casos.

${ }^{8}$ Segundo Bardin (2004), "[...] o tema é a unidade de significação que se libera naturalmente de um texto analisado segundo certos critérios relativos à teoria que serve de guia à leitura. $\mathrm{O}$ texto pode ser recortado em idéias constituintes, em enunciados e em proposições portadores de significações isoláveis. [...] Fazer uma análise temática consiste em descobrir os "núcleos de sentido" que compõem a comunicação e cuja presença ou freqüência de aparição podem significar alguma coisa para o objectivo analítico escolhido. [...] o tema é geralmente utilizado como unidade de registro para estudar motivações de opiniões, de atitudes, de valores, de crenças, de tendências, etc." (Bardin, 2004, p.99)

Quanto à utopia, afirma Mannheim (1968, p.216) que 
Um estado de espírito é utópico quando está em incongruência com o estado de realidade dentro do qual se insere. Esta incongruência é sempre evidente pelo fato de que este estado de espírito na experiência, no pensamento e na prática se oriente para objetos que não existem na situação atual. [...] Iremos nos referir como utópicas somente aquelas orientações que, transcendendo a realidade, tendem, a se transformarem em conduta, a abalar, seja parcial, ou totalmente, a ordem de coisas que prevaleça no momento. Ao limitar o significado do termo "utopia" ao tipo de orientação que transcende a realidade e que, ao mesmo tempo, rompe as amarras da ordem existente, estabelece-se uma distinção entre os estados utópicos e os ideológicos.

Löwy (2000) sintetiza o pensamento Mannheimniano quanto ao fenômeno "Ideologia Total" em suas manifestações de ideologia e utopia: ideologia é o conjunto das concepções, ideias, representações, teorias, que se orientam para a estabilização, ou legitimação, ou reprodução da ordem estabelecida. São todas aquelas doutrinas que têm um certo caráter conservador no sentido amplo da palavra, isto é, consciente ou inconscientemente, voluntária ou involuntariamente, servem à manutenção da ordem estabelecida. Utopias, ao contrário, são aquelas ideias, representações e teorias que aspiram a uma outra realidade. Deste modo, as utopias têm uma função subversiva, uma função crítica e, em alguns casos, uma função revolucionária.

O presente trabalho faz distinção semântica entre o uso acadêmico do termo sociológico "Utopia" (uma das formas de manifestação da Ideologia Total) - que aspira à mudança - e o termo "utopia", alusivo ao uso do senso comum - que o associa à impossibilidade de mudança. Também faz distinção entre Ideologia (Total), fenômeno maior, e ideologia, sua forma de manifestação associada à manutenção da ordem estabelecida e, em decorrência, associada à utopia.

Paradigma corresponde a um conjunto de noções, representações e crenças, compartilhadas por um determinado segmento de sujeitos sociais, tornando-se um referencial para a ação (Paim, 1997). Então, este estudo pressupõe que o conceito de SUS, como paradigma, refere-se ao conceito de "SUS democrático", como visão social de mundo Utópica, de acordo com os ideais estabelecidos pela Reforma Sanitária Brasileira.

\section{Resultados e discussão}

Os cirurgiões-dentistas foram identificados, em seus subgrupos de estudo (Londrina, Curitiba e Docentes), pelas letras L (SUS Tradicional de Londrina), C (SUS ESF de Curitiba) e D (Docentes de Londrina). Logo, L3 refere-se à terceira entrevista do subgrupo do SUS Tradicional, de Londrina; C8, à oitava entrevista do SUS ESF, de Curitiba; e D1, à primeira entrevista do subgrupo dos Docentes, de Londrina. As intervenções do pesquisador, nos diálogos, quando necessárias, foram identificadas por (P).

A partir das entrevistas realizadas, foram identificadas 23 RS relativas ao termo SUS, que foram agrupadas em três categorias ou Sistemas Representacionais: Representações de Desconhecimento; Representações de Realidade; e Representações de Conhecimento (Quadro 1).

No Sistema do Desconhecimento (S1, Quadro 2), verificou-se uma representação-chave para a compreensão do tema de pesquisa: o desconhecimento do SUS, por parte do entrevistado. Este percebe a ausência de referenciais cognitivos que lhe permitam avaliar com justeza o SUS, o que gera uma situação desconcertante: o profissional integra o SUS, mas dele não se reconhece parte.

O fato é emblemático da descontextualização do profissional quanto ao sistema de saúde em que está inserido, seu autodesconhecimento enquanto ator social, no desempenho de suas atividades profissionais. O fato chama a atenção para dois aspectos importantes: a formação profissional e o alcance do ideário da Reforma Sanitária.

Verificou-se, no subgrupo Londrina, um déficit, não de formação técnica, mas de formação política, relativamente ao SUS.

De acordo com Neide Deluiz (1997), o SUS requer um "novo trabalhador", sendo necessário um conjunto de habilidades que contemplem a interação comunicativa e a ampliação do espectro de 
Quadro 1. Representações sociais dos cirurgiões-dentistas quanto ao conceito SUS, por sistemas representacionais. Londrina e Curitiba, 2004.

\begin{tabular}{|c|c|c|}
\hline $\mathrm{N}^{\circ}$ & Representações sociais & Sistemas \\
\hline 1 & Desconhecimento sobre o SUS & \multirow{7}{*}{$\begin{array}{c}\text { S1 } \\
\text { Sistema do Desconhecimento }\end{array}$} \\
\hline 2 & O dentista fora do SUS & \\
\hline 3 & O SUS não resolve & \\
\hline 4 & Desconhecimento do PSF & \\
\hline 5 & O SUS repassador de recursos & \\
\hline 6 & Assistência de má qualidade & \\
\hline 7 & SUS para pobres & \\
\hline 8 & A política atrapalha o SUS & \multirow{7}{*}{$\begin{array}{c}\text { S2 } \\
\text { Sistema da Realidade }\end{array}$} \\
\hline 9 & Dificuldades financeiras do SUS & \\
\hline 10 & Acesso deficiente ao SUS & \\
\hline 11 & Atenção especializada deficiente & \\
\hline 12 & Imagem negativa do SUS na sociedade & \\
\hline 13 & Teoria diferente da prática & \\
\hline 14 & O SUS é inviável ("utopia") & \\
\hline 15 & O dentista dentro do SUS & \multirow{9}{*}{$\begin{array}{c}\text { S3 } \\
\text { Sistema do Conhecimento }\end{array}$} \\
\hline 16 & O SUS como solução & \\
\hline 17 & Reconhecimento do PSF & \\
\hline 18 & Assistência de boa qualidade & \\
\hline 19 & Excelente concepção teórica & \\
\hline 20 & O SUS é viável (Utopia) & \\
\hline 21 & O SUS como processo social & \\
\hline 22 & Compromisso com o SUS & \\
\hline 23 & Participação Popular e Controle Social & \\
\hline
\end{tabular}

funções, superando a educação exclusivamente tecnicista. Para a autora, a formação do profissional da saúde deve ter por base alguns níveis de competências associados às respectivas categorias de capacidades e habilidades. Entre elas, estão as competências: técnica (capacidade de dominar as tarefas, regras e procedimentos da área específica de trabalho); organizacional (capacidade de autoplanejamento e de auto-organização, na medida em que desenvolve a flexibilidade no processo de trabalho); comunicativa (com seu grupo de trabalho); social (uso de conhecimentos adquiridos no mundo do trabalho e na vida cotidiana no desempenho de sua função); pessoal (assumir a responsabilidade sobre o trabalho); de cuidado (capacidade de interagir com o paciente, levando em consideração suas necessidades e escolhas); de serviço (compreensão dos impactos que suas ações terão direta ou indiretamente sobre os serviços ou usuários) e sociopolítica (capacidade de refletir sobre a esfera do mundo do trabalho).

A Constituição Federal de 1988, art. 200, inciso III, declara competência da gestão do SUS “o ordenamento da formação de recursos humanos da área da saúde" (Brasil, 2003, p.40). A Lei 8.080/90, art. 27 (Brasil, 1990), também prevê seja esta uma atribuição do SUS em todos os níveis de ensino, inclusive de pós-graduação, além da elaboração de programas de permanente aperfeiçoamento de pessoal, o que vem sendo apontado nas VIII, IX, X e XI Conferências Nacionais de Saúde (Ceccim, Armani, Rocha, 2002).

Desde a criação do primeiro curso de Odontologia do país, na Bahia, em 1882, até a implantação das Diretrizes Curriculares Nacionais dos Cursos de Graduação em Odontologia (Fernandes Neto, 2010; Terada, Nakama, 2004), tem havido a preocupação de se adequarem os currículos odontológicos, que 
Quadro 2. Representações sociais e narrativas dos cirurgiões-dentistas sobre o SUS, referentes ao Sistema do Desconhecimento. Londrina e Curitiba, 2004.

\begin{tabular}{|c|c|}
\hline Representações sociais & Narrativas do Sistema do Desconhecimento \\
\hline $\begin{array}{l}1 \text { Desconhecimento } \\
\text { sobre o SUS }\end{array}$ & $\begin{array}{l}\text { [...] Essa parte do SUS, vou falar a verdade para você, eu não tenho muita noção de como } \\
\text { funciona mesmo o SUS em si, como um todo, eu não faço muita idéia, eu estou um } \\
\text { pouquinho bitolado na área da odontologia, então no SUS, eu não tenho muita noção de } \\
\text { como funciona, de como que é a hierarquia, como que eles fazem, como que eles vêem a } \\
\text { demanda, como que eles tentam suprir essa demanda, como que eles fazem a distribuição } \\
\text { de profissionais, isso eu não tenho noção nenhuma, preciso me informar melhor... (L5) }\end{array}$ \\
\hline $\begin{array}{l}2 \text { O dentista fora do } \\
\text { SUS }\end{array}$ & $\begin{array}{l}\text { [...] no meu posto, onde eu atendo, existia um dentista credenciado pelo SUS, que a gente } \\
\text { dava guia, só que agora ele se descredenciou e a gente não tem para onde jogar esses } \\
\text { pacientes [adultos], se descredenciou justamente acho que pelo baixo preço que o SUS } \\
\text { paga para os dentistas, parece que era um absurdo o que ele recebia, e ele se } \\
\text { descredenciou. [...] O SUS deveria ser muito melhor administrado, muito melhor trabalhado } \\
\text { isso daí, porque é uma judiação mesmo, como eu falei com você lá, aquele dentista, a gente } \\
\text { tinha uma noção de como ele trabalhava, você falava assim: Como uma pessoa pode } \\
\text { trabalhar numa estrutura tão pequena que é dado, numa estrutura tão.... a odontologia } \\
\text { pelo SUS, [risos] as vezes fica deixada bem de lado mesmo. [ -Você faz parte do SUS } \\
\text { também? (P)] - Não, pelo SUS não. A gente é municipalizado, pela rede... [- como você vê } \\
\text { esse atendimento da rede? (P)] -Muito bom, muito bom... [L1]. }\end{array}$ \\
\hline 3 O SUS não resolve & $\begin{array}{l}\text { Olha, eu acho o SUS um grande problema [risos]... Eu acho o SUS solução pra quase nada, } \\
\text { viu, na odontologia [é] que eu estou falando isto pra você (D9). }\end{array}$ \\
\hline $\begin{array}{l}4 \text { Desconhecimento } \\
\text { do PSF }\end{array}$ & $\begin{array}{l}\text { Agora, o SUS eu não sei, o SUS não tem nada com o Programa de Saúde da Família, ou tem } \\
\text { também? Acho que não, não é? É mais, mais separado isso [...] (L6). }\end{array}$ \\
\hline $\begin{array}{l}5 \text { O SUS repassador de } \\
\text { recursos }\end{array}$ & $\begin{array}{l}\text { Eu acho que [o SUS] é um atendimento muito deficitário no país, ele existe mas não cumpre } \\
\text { o papel, não tem o que falar, não faz o papel que deveria fazer. É uma forma só de, talvez } \\
\text { em temos de repasse de dinheiro, para instituições, mas ele em si não funciona. É isso! (D8). }\end{array}$ \\
\hline $\begin{array}{l}6 \text { Assistência de má } \\
\text { qualidade }\end{array}$ & $\begin{array}{l}\text { [Vejo o SUS] Com muita tristeza, com muita tristeza mesmo. Eu creio que poderia ter um } \\
\text { modelo mais abrangente, qualidade, poderia melhorar muito na qualidade [...] (D5). }\end{array}$ \\
\hline 7 SUS para pobres & $\begin{array}{l}\text { [...] eu acho que saúde [...] é uma coisa muito cara para ser extensiva a todos, eu acho que } \\
\text { tinha que ser proporcional: o carente deveria ter tudo de graça, aquele que não consegue } \\
\text { pagar tudo, ter uma parcela, e aquele que pode pagar, pagar. A saúde é cara, ela onera } \\
\text { muito o Estado, quero dizer, a gente mesmo, porque o Estado é a gente, é imposto, então } \\
\text { isso onera muito, [...] eu não acho que seja viável, eu vou ser sincero para você, esse posto } \\
\text { [de saúde] aqui é um pouco diferenciado, você vê muitos paciente que antes seriam de } \\
\text { convênios ou até mesmo de consultório particular, que tem toda condição de fazer um } \\
\text { tratamento em consultório particular; não fazem, e vem aqui, e muitas vezes esse paciente } \\
\text { está tomando a vaga de um paciente que não tem condições, tem lista de espera, aí eu } \\
\text { tenho a lista de espera, então este paciente pode estar tomando a vaga de um paciente } \\
\text { que não teria condições financeiras nenhuma (L8). }\end{array}$ \\
\hline
\end{tabular}

evoluíram de uma concepção originariamente tecnicista ao mais amplo estabelecimento do perfil do egresso/profissional, conforme propõem as referidas Diretrizes no artigo $3^{\circ}$ da Resolução do Conselho Nacional de Educação/Câmara de Educação Superior (CNE/CES), de 19 de fevereiro de 2002:

O Curso de Graduação em Odontologia tem como perfil do formando egresso/profissional o Cirurgião-Dentista, com formação generalista, humanista, crítica e reflexiva, para atuar em todos os níveis de atenção à saúde, com base no rigor técnico e científico. Capacitado ao exercício de atividades referentes à saúde bucal da população, pautado em princípios éticos, legais e na compreensão da realidade social, cultural e econômica do seu meio, dirigindo sua atuação para a transformação da realidade em benefício da sociedade. (Brasil, 2002, p.10) 
Ao que se junta o Programa Nacional de Reorientação da Formação Profissional em Saúde (PróSaúde), lançado em 2005, de iniciativa do Ministério da Saúde, que se destina à reorientação da formação de profissionais de saúde por uma escola integrada ao serviço público de saúde e que dê respostas às necessidades concretas da população brasileira na formação de recursos humanos, na produção do conhecimento e na prestação de serviços, direcionados a construir o fortalecimento do SUS (Brasil, 2010).

No campo da gestão da saúde bucal, vislumbra-se uma complexa agenda em que a formação de recursos humanos toma parte (Frazão, 2009). A III Conferência Nacional de Saúde Bucal (CNSB) entendeu que, quanto à formação e trabalho em saúde bucal, o sistema de Ensino Superior não está cumprindo o seu papel na formação de profissionais comprometidos com o SUS e com o controle social. A formação dos trabalhadores da saúde não se orienta pela compreensão crítica das necessidades sociais em saúde bucal (Narvai, 2006). Segundo a III Conferência Nacional de Saúde Bucal (Brasil, 2005, p.70),

A expansão das equipes de Saúde da Família deixou evidentes as limitações do perfil atual de formação, como um ponto de estrangulamento na implementação do Sistema Único de Saúde (SUS). Os componentes técnicos da educação na graduação e pós-graduação em saúde geralmente não estão voltados para as necessidades de saúde da população nem para o emprego ou criação de tecnologias assistenciais inovadoras.

Conforme Pucca Junior (2004), na saúde bucal, somos herdeiros da tradição materno-infantil, e os serviços necessitam se organizar e necessitam de outras demandas de formação profissional:
O debate se coloca quando se busca a adequação profissional frente às demandas sociais necessárias, sejam elas de natureza pública ou privada, que são, inevitavelmente, as necessidades do conjunto da sociedade, ou seja, o que se espera que o profissional desempenhe após o seu ingresso no mercado de trabalho. (Pucca Junior, 2004, p.151-2)

Segundo Paim (2009), a questão dos recursos humanos, presente na agenda política da $8^{a}$. CNS, não encontrou ressonância nem prioridade, e constitui grande dívida do Estado brasileiro com aqueles que constroem o SUS a cada dia.

Tânia Nunes, em entrevista a Noronha et al. (2002, p.12), declara que "A questão da formação profissional está na Reforma desde a sua origem. Já naquela época, se via a necessidade de um salto qualitativo dado pela politização e pela inquietação que deveriam caracterizar uma educação profissional mais comprometida com o movimento típico da reforma da saúde".

A formação de recursos humanos para a saúde diferencia duas modalidades de educação no trabalho: a Educação Continuada em Saúde (ECS) da Educação Permanente em Saúde (EPS). A Educação Continuada é uniprofissional, visa uma pratica autônoma, enfoca temas de especialidades, objetiva atualização técnico-científica, esporádica, baseia-se na pedagogia da transmissão, e resulta em apropriação. A Educação Permanente é multiprofissional, visa uma prática institucionalizada, enfoca problemas de saúde, objetiva a transformação das práticas técnicas e sociais, é contínua, com pedagogia centrada na resolução de problemas e resultando em mudança (Mancia, Cabral, Koerich, 2004; Almeida, 1999).

O Ministério da Saúde, ao instituir a Política Nacional de Educação Permanente em Saúde, afirma que "os processos de educação permanente em saúde têm como objetivos a transformação das práticas profissionais e da própria organização do trabalho" (Brasil, 2009, p.20).

Para Feuerwerker (2007), a educação dos profissionais de saúde tem uma importância grande na conformação de conceitos e de práticas na área da saúde:

[...] em comum com o movimento da reforma sanitária brasileira, o movimento de mudanças na formação tem o compromisso ético-político com a saúde da população brasileira e com os princípios do SUS. Educação na saúde, então, é um campo a ser trabalhado do ponto de vista da produção de conhecimento e das práticas sociais. Essa é uma tarefa para todas as 
profissões da saúde. Mais: é uma tarefa para todos os campos de saber entre-cruzados com a saúde e com a educação na produção do compromisso ético-político que norteia o movimento da reforma sanitária brasileira. (Feuerwerker, 2007, p.4)

Outro aspecto fundamental que deve ser tratado na análise do desconhecimento do SUS pelos profissionais do SUS é o referente ao alcance dos seus conceitos e princípios. Muitos profissionais do SUS não são atingidos pela retórica da Reforma Sanitária, e, mais que isto, nem mesmo a conhecem.

Algumas representações do SUS o associam ao atendimento prestado por dentistas em seus consultórios privados, remunerados por um sistema de credenciamento. Este modelo de financiamento e repasse de recursos, conhecido por Plano de Pronta Ação (PPA), surgiu em 1974, ano de criação do Ministério da Assistência e Previdência Social, e universalizou a atenção às urgências (Mendes, 1992). Esta forma de assistência é hoje residual no SUS para a atenção odontológica, configurando mais exceção que regra nos modelos de atenção vigentes. Ainda assim, o SUS foi significativa e anacronicamente relacionado ao PPA, e o "dentista do SUS", ao "dentista do PPA", do período INAMPS e, portanto, pré-SUS.

Ocorre a "inampização" do SUS, forma de descentralização das ações de saúde com transferência de gestão, sem mudança do modelo assistencial, revelando-se um dos nichos mais nítidos de apropriação privada da rés pública, fenômeno conhecido como privatização do Estado. O município é visto como mero prestador de serviços, seja à previdência social (quando existia o INAMPS), seja ao SUS (após a extinção do INAMPS) (Mendes, 1992).

Em parte do subgrupo dos docentes, o SUS não é mais percebido como INAMPS, mas ainda o é como o SUS comprador de serviços. O SUS "inampizado" é percebido como financiador das atividades clínicas, mas não como modelo de lógica assistencial, como pode ser observado em clínicas odontológicas de universidades, elementos constitutivos de um SUS que, conquanto as subvencione, permanece invisível, subliminar, ignoto a alunos e docentes.

Neste contexto, a ESF apresenta-se como um instituto distante, afastado da realidade do entrevistado, alheio à sua percepção como importante tentativa de reorganização da Atenção Básica. $O$ período de coleta de dados permitiu captar, nesta representação, o momento histórico vivido pelos profissionais de Londrina, que assistiam, com distanciamento, ao início da implantação da ESF no município, representação associada: à insegurança dos profissionais quanto à mudança do modelo assistencial que a ESF suscitava; ao desconhecimento mesmo do SUS e, consequentemente, da ESF; às dificuldades estruturais de sua implantação; e, ainda, ao receio de que o evento pudesse pôr a perder todo um trabalho preventivo bem-sucedido, ainda que focado em faixas etárias limitadas. Apesar de dúvidas e receios, verificou-se o reconhecimento de que a ESF está associada a um maior acesso aos serviços de saúde, ainda que percebido como um "atendimento para adultos", em distinção ao atendimento infanto-juvenil tradicionalmente ofertado. Esta identificação "ESF dentista para adultos", que muito tem prosperado atualmente, configura a negação do desafio da integralidade que o justifica como estratégia de reorganização da Atenção Básica.

O primeiro sistema evidencia as representações ligadas ordinariamente ao desconhecimento do SUS, o que determina uma autopercepção externa ao mesmo, refletindo na incompreensão do sistema. Esta incompreensão determina uma avaliação do SUS pelas experiências da realidade traduzidas pelo senso comum. O SUS é, assim, identificado como ausência de solução e, no limite, como o próprio problema. Nesta lógica do desconhecimento, a ESF não é uma estratégia estruturante de um modelo assistencial democrático e equitativo, mas sim um ente distante e indefinível, citado pelos noticiários de televisão e, portanto, dissociado da concretude da prática profissional, no cotidiano das Unidades Básicas de Saúde. O SUS é ainda identificado com os antigos prestadores do INAMPS, ou a um mero repassador de recursos financeiros, no fenômeno da "inampização" do SUS, mais característico nas instituições de ensino. Neste contexto, o SUS está vinculado, irremediavelmente, a um atendimento de baixa qualidade, débil, mínimo, não resolutivo, como um serviço pobre para gente pobre, conforme Paim (2002). Esta representação consubstancia a própria negação do Sistema Único e dos objetivos da Reforma Sanitária; logo, é a percepção do SUS como o não-SUS, ou, ainda, como o anti-SUS. 
Quadro 3. Representações sociais e narrativas dos cirurgiões-dentistas sobre o SUS, referentes ao Sistema da Realidade. Londrina e Curitiba, 2004.

\begin{tabular}{|c|c|}
\hline Representações sociais & Narrativas do Sistema da Realidade \\
\hline $\begin{array}{l}9 \text { Dificuldades financeiras do SUS; } \\
10 \text { Acesso deficiente ao SUS; } \\
11 \text { Atenção especializada deficiente }\end{array}$ & $\begin{array}{l}\text { O problema é quando a situação vai se atrasando, as doenças vão se agravando, } \\
\text { então estão precisando de mais recursos, mais especialidades, mais tecnologia, } \\
\text { de maquinário, você vê que estrangula, que realmente vai ficando muito mais } \\
\text { caro e... uma parcela muito grande da população que fica de fora! (D1). }\end{array}$ \\
\hline 12 Imagem negativa na sociedade & $\begin{array}{l}\text { Nós conseguimos sair daquela velha máxima que dizia: "O [atendimento] } \\
\text { público é de baixa qualidade e não presta". Então eu acho que só de reverter } \\
\text { esta idéia que se tinha, não vou dizer que não tenha, que não exista isto ainda. } \\
\text { O serviço público ainda está vinculado à imagem dos antigos prestadores do } \\
\text { INPS, que serviço público era pra mutilar, era pra arrancar dentes, era para fazer } \\
\text { obturação de baixa qualidade. Mas felizmente esse quadro, essa visão, ele está } \\
\text { mudando [...] (D7). }\end{array}$ \\
\hline 13 Teoria diferente da prática & $\begin{array}{l}\text { O SUS é um sistema que exemplifica o que eu disse logo no início: O discurso é } \\
\text { um, a prática é outra. Acho que o discurso do SUS com a prática não tem nada a } \\
\text { ver uma coisa com a outra (D5). }\end{array}$ \\
\hline
\end{tabular}

O Sistema da Realidade (S2, Quadro 3) expressa, em suas representações, todas as características vivenciadas no dia a dia dos serviços públicos de saúde. A política é vista como um fator desorganizador do SUS: a falta de prioridade política e a corrupção dos entes públicos determinariam um subfinanciamento do setor Saúde, alimentando, assim, a percepção de uma das maiores debilidades do sistema, sua razão de ser e, também, seu maior desafio: a dificuldade de acesso universal físico ao sistema. Não é por outra razão que o levantamento do Ministério da Saúde e do CONASS (Biancarelli, 2003) apontava as filas de espera como a maior queixa dos usuários. As dificuldades de acesso irradiamse pelos demais níveis de atenção, como o secundário e o terciário, e, também, nos serviços odontológicos, a deficiência quanto ao atendimento de especialidades foi captada enquanto representação da realidade do SUS.

As dificuldades concretas na operacionalização diária põem em cheque a real capacidade de atender às expectativas e às demandas da sociedade e podem ser decisivas na elaboração das representações do SUS pelos sujeitos sociais: a frustração e o ceticismo. Através da frustração nas experiências do passado e do presente, o profissional desacredita do SUS como resposta viável para o futuro. As falas de C4, D8 e L8 mostram o tênue limite entre crença e descrença no SUS, e o processo frustração/ceticismo em ação:

"(P) Você acha [o SUS] realizável?: - Eu acho. Olha, eu quero achar que seja realizável. Eu quero achar. Como eu falei: Não quero perder as esperanças. Mas acho que ainda é bem difícil e que tem um longo caminho pela frente para ser seguido. Não é fácil". (C4)

“- Eu acho que [o SUS] é um atendimento muito deficitário no país, ele existe mas não cumpre o papel, não tem o que falar, não faz o papel que deveria fazer. É uma forma só de, talvez em termos de repasse de dinheiro, para instituições, mas ele em si não funciona. É isso!". (D8)

“- Eu sou muito cético quanto ao SUS, eu acho que saúde [...] é uma coisa muito cara para ser extensiva a todos, eu acho que tinha que ser proporcional: eu acho que o carente 
deveria ter tudo de graça, aquele que não consegue pagar tudo, ter uma parcela, e aquele que pode pagar, pagar. [...] eu não acho que seja viável [...]". (L8)

O homem se faz livre e autônomo na medida em que delibera, fazendo uso da razão (Kant, 1995). Neste aspecto, é relevante que a aceitação do SUS como referência, pelo profissional, uma deliberação ética e política, também derive de uma escolha racional e livre em acreditar, mobilizando recursos do pensamento e da vontade na perspectiva de alcançar os objetivos colimados. Do conflito entre frustração/ceticismo e esperança/perseverança, apenas o processo histórico validará ou não, a posteriori, as opções do presente. Entretanto, a fala de C4: "eu quero achar que o SUS seja realizável, não quero perder as esperanças" é suficientemente eloquente da centralidade desta categoria.

Corroboram esta interpretação os resultados de Oliveira et al. (2008), que refletem as principais características e dificuldades do sistema de saúde brasileiro, tais como os recursos humanos, o financiamento, as condições do atendimento da população, a participação e o acesso da clientela ao sistema

bem como um conhecimento fragmentado dos princípios que regem o SUS pelo grupo estudado. A dimensão das atitudes, presente na representação, revela dois posicionamentos distintos: um negativo referido às dificuldades enfrentadas para a implantação do SUS; e outro positivo relativo aos direitos assegurados pelo novo sistema. (Oliveira et al., 2008, p.204)

Por fim, o Sistema do Conhecimento (S3, Quadro 4), que opera em lógica diversa. Este conjunto representacional está associado às aspirações de efetivação do SUS como modelo alternativo de atenção à saúde. Este sistema parte, primeiramente, do autoconhecimento do profissional sobre o desempenho de seu papel, enquanto ator na sociedade. O entendimento e a segurança em se perceber parte de um todo e, por isso, parte do SUS, possibilita a compreensão dos propósitos da Reforma Sanitária, e o SUS como solução às desigualdades e instrumento de justiça social. A ESF deixa de ser um instrumento de propaganda político-administrativa e passa a ser uma formulação organizacional e paradigmática de um novo modelo de atenção em saúde. Surgem, então, as representações de qualidade do sistema, de uma prática integral e universalista. A excelência da concepção teórica é reconhecida pelo profissional, que percebe a necessidade e premência de sua implementação efetiva. No paradoxo da realidade vivida e da realidade a ser construída, o profissional entende a viabilidade do projeto, ainda que sem a ilusão do imediatismo e da facilidade, reconhecendo, também, a importância de sua participação ativa na construção da realidade projetada. Este ciclo se completa quando o profissional transcende sua própria existência e se plenifica na relação social, valorizando, assim, a Participação Popular e o Controle Social, por entendê-los instrumentos de legitimação e emancipação da sociedade da qual faz parte.

Conforme o Quadro 5, o subgrupo dos profissionais de Londrina, no modelo tradicional ainda não integrado à ESF, apresentou, predominantemente, representações de desconhecimento e de realidade do SUS, impossibilitando sua identificação com a proposta. Altamente significativo e revelador é o fato de que a única entrevista representativa de conhecimento e utopia, crença e compromisso com o SUS, no subgrupo Londrina, adveio de profissional membro da equipe gestora dos serviços odontológicos municipais (L4), divergindo francamente das demais entrevistas do subgrupo. Por seu turno, o subgrupo dos docentes de Londrina mostrou-se o mais heterogêneo, possuindo desde profissionais totalmente alheios e desinformados, passando por outros matizes de desinformação, descrença e/ou descaso, até outros, claramente identificados com os princípios e pressupostos do SUS. Suas representações pulverizaram-se por todos os sistemas de representação, caracterizando preocupante lacuna quanto ao SUS, em prejuízo da formação profissional de seus alunos, temporariamente tutelados mas, potencialmente, profissionais autônomos (lato sensu), cidadãos esclarecidos e comprometidos com o SUS e com a sociedade à qual prestarão serviço.

O subgrupo dos profissionais da ESF de Curitiba apresentou resultados nitidamente diferentes dos demais grupos, compartilhando representações de realidade e de conhecimento do SUS, sem produzir concepções de desconhecimento, independente do tempo de atuação e da idade - o que sugere ser a ESF um modelo mais adequado ao entendimento da estrutura do sistema, possibilitando maior consciência social e política do profissional. 
Quadro 4. Representações sociais e narrativas dos cirurgiões-dentistas sobre o SUS, referentes ao Sistema do Conhecimento. Londrina e Curitiba, 2004.

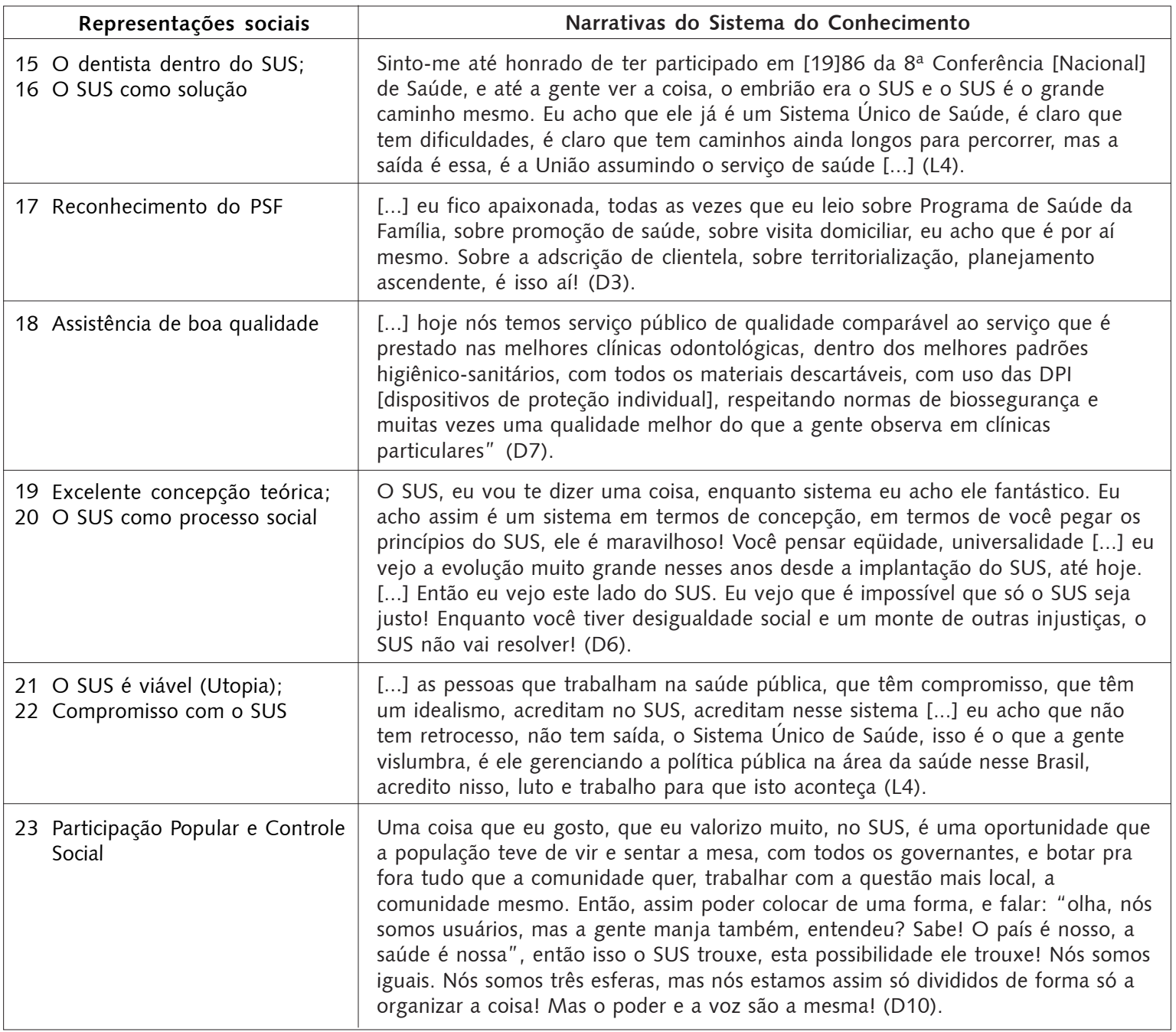

Atributos de gênero não puderam responder pelas diferentes representações observadas, ao menos entre os subgrupos Londrina e Curitiba, pois, entre este último, contaram-se apenas mulheres, o que limitou possíveis conclusões. Entre os subgrupos Docentes e Londrina, não houve diferença quanto ao gênero. Referentemente ao tempo de atuação profissional e a idade dos entrevistados, os fatores não explicaram as RS entre o subgrupo Londrina, Curitiba e Docentes, mostrando-se irrelevantes.

Além do conceito do SUS, outras dimensões influenciam na elaboração das RS sobre o SUS: a relação do profissional com o próprio conceito, e seu posicionamento frente a este. As representações de desconhecimento se associam ao conceito de "SUS para pobres", em uma relação de negação do SUS, onde o profissional se posiciona fora do SUS; as representações de realidade se associam ao conceito de "SUS real", em uma relação de aceitação parcial do SUS, onde o profissional se posiciona à sua margem; e as representações de conhecimento se associam aos conceitos de "SUS formal" e "SUS democrático", em uma relação de aceitação plena do SUS, onde o profissional se posiciona dentro do SUS. No subgrupo Londrina, houve predominância de representações de desconhecimento e de 
Quadro 5. Distribuição das representações sociais dos cirurgiões-dentistas sobre o SUS, por profissional, subgrupo de pesquisa, sistema de representações, sexo e idade/tempo de atuação profissional. Londrina e Curitiba, 2004.

\begin{tabular}{|c|c|c|c|c|c|c|c|c|c|c|c|c|c|c|c|c|c|c|c|c|c|c|c|c|c|c|c|c|}
\hline \multirow[b]{2}{*}{ Sis. } & \multirow[b]{2}{*}{$\mathrm{N}^{\circ}$} & \multirow[b]{2}{*}{ Representações sociais } & \multicolumn{8}{|c|}{ Londrina } & \multicolumn{8}{|c|}{ Curitiba } & \multicolumn{10}{|c|}{ Docentes } \\
\hline & & & 1 & 2 & 3 & 4 & 5 & 6 & 7 & 8 & 1 & 2 & 3 & 4 & 5 & 6 & 7 & 8 & 1 & 2 & 3 & 4 & 5 & 6 & 7 & 8 & 9 & 10 \\
\hline \multirow{7}{*}{ S1 } & 1 & $\begin{array}{l}\text { Desconhecimento sobre o } \\
\text { SUS }\end{array}$ & & & $\mathrm{F}$ & & $M$ & $\mathrm{~F}$ & $\mathrm{~F}$ & & & & & & & & & & & & & & & & & & & \\
\hline & 2 & O dentista fora do SUS & $\mathrm{F}$ & & $\mathrm{F}$ & & $M$ & $\mathrm{~F}$ & $\mathrm{~F}$ & & & & & & & & & & & & & $M$ & & & & & M & \\
\hline & 3 & O SUS não resolve & $\mathrm{F}$ & & & & & $\mathrm{F}$ & & & & & & & & & & & & & & $M$ & $M$ & & & $\mathrm{~F}$ & M & \\
\hline & 4 & Desconhecimento do PSF & & & $\mathrm{F}$ & & & $\mathrm{F}$ & & & & & & & & & & & & & & $M$ & & & & & & \\
\hline & 5 & O SUS repassador de recursos & $\mathrm{F}$ & & $\mathrm{F}$ & & & $\mathrm{F}$ & $\mathrm{F}$ & & & & & & & & & & $\mathrm{F}$ & & & $M$ & & & & $\mathrm{~F}$ & M & \\
\hline & 6 & Assistência de má qualidade & $\mathrm{F}$ & & & & $M$ & & $\mathrm{~F}$ & & & & & & & & & & & & & $M$ & & & & & & \\
\hline & 7 & SUS para pobres & & & & & & & & $M$ & & & & & & & & & & & & & & & & & & \\
\hline \multirow{7}{*}{ S2 } & 8 & A política atrapalha o SUS & & $\mathrm{F}$ & & & & & & & & & & $\mathrm{F}$ & $\mathrm{F}$ & & & & & & $\mathrm{F}$ & & $M$ & & & & & \\
\hline & 9 & $\begin{array}{l}\text { Dificuldades financeiras do } \\
\text { SUS }\end{array}$ & $\mathrm{F}$ & $\mathrm{F}$ & & & M & $\mathrm{F}$ & & M & $\mathrm{F}$ & & & & $\mathrm{F}$ & $\mathrm{F}$ & & & & & $\mathrm{F}$ & & & & & & M & \\
\hline & 10 & Acesso deficiente ao SUS & $\mathrm{F}$ & $\mathrm{F}$ & $\mathrm{F}$ & & $M$ & $\mathrm{~F}$ & & $M$ & $\mathrm{~F}$ & & & $\mathrm{~F}$ & $\mathrm{~F}$ & & $\mathrm{~F}$ & $\mathrm{~F}$ & $\mathrm{~F}$ & & $\mathrm{~F}$ & & $M$ & & $\mathrm{~F}$ & $\mathrm{~F}$ & & $\mathrm{~F}$ \\
\hline & 11 & $\begin{array}{l}\text { Atenção especializada } \\
\text { deficiente }\end{array}$ & & & $\mathrm{F}$ & & & $\mathrm{F}$ & & & & & & & & $\mathrm{F}$ & & $\mathrm{F}$ & $\mathrm{F}$ & & & M & & & & & & \\
\hline & 12 & $\begin{array}{l}\text { Imagem negativa na } \\
\text { sociedade }\end{array}$ & & $\mathrm{F}$ & $\mathrm{F}$ & & & & & & $\mathrm{F}$ & $\mathrm{F}$ & & & & & & $\mathrm{F}$ & $\mathrm{F}$ & & $\mathrm{F}$ & & & & $\mathrm{F}$ & & & \\
\hline & 13 & Teoria diferente da prática & & & & & & & & & & & & $\mathrm{F}$ & $\mathrm{F}$ & & & & & & & & $M$ & & & & & \\
\hline & 14 & O SUS é inviável ("utopia") & & $\mathrm{F}$ & & & & & & $M$ & $\mathrm{~F}$ & & & & $\mathrm{~F}$ & & $\mathrm{~F}$ & & & & & M & & & & $\mathrm{F}$ & $M$ & \\
\hline \multirow{9}{*}{ S3 } & 15 & O dentista dentro do SUS & & & & M & & & & & $\mathrm{F}$ & $\mathrm{F}$ & $\mathrm{F}$ & $\mathrm{F}$ & $\mathrm{F}$ & $\mathrm{F}$ & $\mathrm{F}$ & $\mathrm{F}$ & & $\mathrm{F}$ & $\mathrm{F}$ & M & & & $\mathrm{F}$ & & & $\mathrm{F}$ \\
\hline & 16 & O SUS como solução & & & & M & & & & & & & $\mathrm{F}$ & & & & $\mathrm{F}$ & & & & $\mathrm{F}$ & & & & $\mathrm{F}$ & & & $\mathrm{F}$ \\
\hline & 17 & Reconhecimento do PSF & & $\mathrm{F}$ & & M & & & & & & $\mathrm{F}$ & & & & $\mathrm{F}$ & & & & & $\mathrm{F}$ & & & & $\mathrm{F}$ & & & \\
\hline & 18 & Assistência de boa qualidade & & & & $M$ & & & & & & $\mathrm{~F}$ & & & $\mathrm{~F}$ & & $\mathrm{~F}$ & & & & & & & & $\mathrm{~F}$ & & & \\
\hline & 19 & Excelente concepção teórica & & & & & & & & & & & $\mathrm{F}$ & & $\mathrm{F}$ & & & & & $\mathrm{F}$ & $\mathrm{F}$ & & M & $\mathrm{F}$ & $\mathrm{F}$ & & & $\mathrm{F}$ \\
\hline & 20 & O SUS é viável (Utopia) & & & & M & & & & & & $\mathrm{F}$ & $\mathrm{F}$ & $\mathrm{F}$ & & $\mathrm{F}$ & & & & $\mathrm{F}$ & & & $M$ & & $\mathrm{~F}$ & & & $\mathrm{~F}$ \\
\hline & 21 & O SUS como processo social & & & & M & & & & & & & & $\mathrm{F}$ & & $\mathrm{F}$ & & & & $\mathrm{F}$ & $\mathrm{F}$ & & & $\mathrm{F}$ & $\mathrm{F}$ & & & $\mathrm{F}$ \\
\hline & 22 & Compromisso com o SUS & & & & M & & & & & & & $\mathrm{F}$ & & & $\mathrm{F}$ & & & & $\mathrm{F}$ & $\mathrm{F}$ & & & & & & & $\mathrm{F}$ \\
\hline & 23 & $\begin{array}{l}\text { Participação Popular/Controle } \\
\text { Social }\end{array}$ & & & & & & & & & & $\mathrm{F}$ & & & & $\mathrm{F}$ & & & & & $\mathrm{F}$ & & $M$ & & & & & $\mathrm{~F}$ \\
\hline
\end{tabular}


realidade; no subgrupo Curitiba, predominaram representações de conhecimento e de realidade; no subgrupo Docentes, as representações distribuíram-se entre os três sistemas, de desconhecimento, de realidade e de conhecimento do SUS.

O conhecimento enquanto elemento estruturante para o estabelecimento do SUS como referência para os profissionais é hipótese plausível. Contudo, caracteriza-se elemento necessário, mas não suficiente: o mero conhecimento do SUS não basta para a efetiva manutenção da estrutura representacional de conhecimento, Utópica. Se apartado da vontade, frente ao adverso contexto da realidade, o conhecimento pode produzir ações sociais de manutenção das iniquidades, via atitude cética, de descrença relacionada às perspectivas do SUS. Se a atitude não contempla a perspectiva de mudança, configura-se assim, também, uma postura ideológica. Tanto o sistema do Desconhecimento quanto o do Conhecimento compartilham as representações de Realidade, e encontram, na frustração quanto às expectativas do SUS, passagem para a visão ideológica, através do ceticismo. Dessa forma, o ceticismo e a frustração são mecanismos de reprodução da ideologia referente ao SUS.

Paim (2002) vislumbrou este risco, quando aventou a possibilidade de os princípios finalísticos do SUS serem desmoralizados e transformados em reação contra o SUS e a Reforma Sanitária, em vez de estimularem novos esforços e forças interessados em reduzir a distância entre a retórica e a realidade.

Assim, a questão decisiva é a viabilidade ou não do SUS, na percepção dos profissionais entrevistados. A representação da viabilidade do projeto SUS, associada ao conhecimento, define o profissional que tem o SUS por paradigma.

\section{Conclusões}

Este trabalho propôs verificar a validade do SUS como referencial para o cirurgião-dentista. Para isto, é necessário, primeiramente, que ele seja conhecido. Este trabalho demonstrou que o fato, em parte, não ocorria, seguindo o SUS como um grande desconhecido. E ainda: somente o conhecimento não garante o reconhecimento do SUS enquanto referência válida, se sua ciência estiver apartada de uma visão social de mundo Utópica, transformadora. Para que o SUS seja válido enquanto paradigma para seus profissionais, é necessário que seja aceito em duas dimensões diferentes: a dimensão cognitiva e a dimensão Ideológica (Ideologia Total).

As representações dos entrevistados evidenciaram três possibilidades: a) Desconhecimento do SUS; b) Conhecimento e ceticismo; c) Conhecimento e Utopia. A primeira possibilidade não permite o SUS como referencial, por deficiência do pressuposto mínimo: o conhecimento de seus princípios. $\mathrm{Na}$ segunda, há relativo conhecimento do SUS, mas a realidade e suas dificuldades concretas não possibilitam a crença na viabilidade do projeto da Reforma Sanitária, conduzindo a um ceticismo mortal. Estas duas primeiras possibilidades produzem, por caminhos diferentes, o mesmo resultado: uma postura de natureza e consequências nitidamente ideológicas, fora do SUS ou à margem deste, porquanto, na negação ou aceitação parcial do SUS, a realidade é mantida e reproduzida, em todas as suas iniquidades. A terceira possibilidade é a que atinge os fins da Reforma Sanitária e a sustenta. Com o conhecimento do SUS associado à Utopia, ao desejo ativo de mudança, à crença na viabilidade do projeto SUS, os ideais da Reforma Sanitária podem se concretizar. Conclui-se que o SUS é apenas parcialmente reconhecido como referencial cognitivo e político-ideológico, para a atenção odontológica, pelos cirurgióes-dentistas. O desenvolvimento deste paradigma contribuirá com a garantia dos pressupostos de universalidade/equidade/integralidade do SUS, a refletirem, no Brasil, por vocação constitucional, uma sociedade consciente, autônoma, democrática, justa e solidária. 


\section{Colaboradores}

Sérgio Xavier de Camargo e Luiza Nakama participaram, igualmente, de todas as etapas de elaboração do artigo. Luiz Cordoni Junior participou de sua discussão, da redação e da revisão do texto.

\section{Referências}

ALMEIDA, M.J. Educação médica e saúde: possibilidades de mudança. Londrina: EDUEL, 1999.

BARDIN, L. Análise de conteúdo. 3.ed. Lisboa: Edições 70, 2004.

BERGER, P.L.; LUCKMANN, T. A construção social da realidade: tratado de sociologia do conhecimento. 21.ed. Petrópolis: Vozes, 2002.

BIANCARELLI, A. Para 42\%, sigla SUS não é confiável. Folha de São Paulo, São Paulo, 28 abr. 2008. Cotidiano. Disponível em: <http://www1.folha.uol.com.br/fsp/cotidian/ ff2804200301.htm>. Acesso em: 25 ago. 2009.

BRASIL. Ministério da Saúde. Programa Nacional de Reorientação da Formação Profissional em Saúde. Disponível em: <http://portal.saude.gov.br/portal/sgtes/ visualizar_texto.cfm?idtxt=22848>. Acesso em: 10 mar. 2010.

. Ministério da Saúde. Secretaria de Gestão do Trabalho e da Educação na Saúde. Departamento de Gestão da Educação em Saúde. Política Nacional de Educação Permanente em Saúde. Brasília: Ministério da Saúde, 2009.

Ministério da Saúde. Secretaria de Atenção à Saúde. Departamento de Atenção Básica. Política Nacional de Atenção Básica. 4.ed. Brasília: Ministério da Saúde, 2007. (Série E. Legislação de Saúde; Série Pactos pela Saúde, 2006, v. 4).

Ministério da Saúde. In: CONFERÊNCIA NACIONAL DE SAÚDE BUCAL, 3., 2004, Brasília. Relatório final... Brasília: Centro de Documentação do Ministério da Saúde, 2005.

Presidência da República. Constituição da República Federativa do Brasil, de 5 de outubro de 1988. Brasília, 2003. Disponível em: <http://www6.senado.gov.br/ con1988/CON1988_05.10.1988/CON1988.pdf>. Acesso em: 28 jan. 2010.

Ministério da Educação. Resolução CNE/CES 3/2002. Institui Diretrizes Curriculares Nacionais do Curso de Graduação em Odontologia. Diário Oficial da União, Brasília, DF, 4 mar. 2002. Seção 1, p.10.

Ministério da Saúde. Lei 8.080/90. Regula, em todo o território nacional, as ações e serviços de saúde, executados isolada ou conjuntamente, em caráter permanente ou eventual, por pessoas naturais ou jurídicas de direito Público ou privado. Diário Oficial da União, Brasília, DF, 19 set. 1990. Seção 1, p.1.

CAMPOS, G.W.S. Desafios políticos e organizacionais do SUS: vinte anos de política pública. Cad. Saude Publica, v.24, n.10, p.2200, 2008.

CECCIM, R.B.; ARMANI, T.B.; ROCHA, C.F. O que dizem a legislação e o controle social em saúde sobre a formação de recursos humanos e o papel dos gestores públicos, no Brasil. Cienc. Saude Colet., v.7, n.2, p.373-83, 2002.

COHN, A. A reforma sanitária brasileira após 20 anos do SUS: reflexões. Cad. Saude Publica, v.25, n.7, p.1614-9, 2009.

CORDÓN, J.A. A inserção da odontologia no SUS: avanços e dificuldades. 1998. Tese (Doutorado) - Faculdade de Ciências da Saúde, Universidade de Brasília, Brasília. 1998. 
DELUIZ, N. Mudanças no mundo do trabalho e necessidades de qualificação de trabalhadores de saúde. Texto apresentado à Reunión de la Red Latinoamericana de Técnicos en Salud. Opas/OMS. Rio de Janeiro, 1997.

FERNANDES NETO, A.J. A evolução dos cursos de Odontologia no Brasil. Disponível em: <http://abeno.org.br/

index.php?option $=$ com_content\&view $=$ article\&id $=79 \&$ Itemid $=61>$. Acesso em: 16 dez. 2010.

FEUERWERKER, L.C.M. Educação na saúde: educação dos profissionais de saúde - um campo de saber e de práticas sociais em construção. Rev. Bras. Educ. Med., v.31, n.1, p.3-4, 2007.

FRAZÃO, P. Vinte anos de Sistema Único de Saúde: avanços e desafios para a saúde bucal. Cad. Saude Publica, v.25, n.4, p.712, 2009.

FRAZÃO, P.; NARVAI, P.C. Saúde bucal no Sistema Único de Saúde: 20 anos de lutas por uma política pública. Saúde Debate, v.33, n.81, p.64-71, 2009.

JUNGES, J.R. Direito à saúde, biopoder e bioética. Interface - Comunic., Saude, Educ., v.13, n.29, p.285-95, 2009.

KANT, I. Fundamentação da metafísica dos costumes. Trad. Paulo Quintela. Lisboa: Edições 70, 1995 (Coleção Textos Filosóficos).

LÖWY, M. Ideologias e ciência social: elementos para uma análise marxista. 14.ed. São Paulo: Cortez, 2000.

MANCIA, J.R.; CABRAL, L.C.; KOERICH, M.S. Educação permanente no contexto da enfermagem e na saúde. Rev. Bras. Enferm., v.57, n.5, p.605-10, 2004.

MANNHEIM, K. Ideologia e utopia. Rio de Janeiro: Zahar, 1968.

MENDES, E.V. O sistema único de saúde: um processo social em construção. In: (Org.). Uma agenda para a saúde. São Paulo: Hucitec, 1996. p.57-98.

As políticas de saúde no Brasil nos anos 80. In: (Org.). Distrito Sanitário: o processo social de mudança das práticas sanitárias do Sistema Único de Saúde. São Paulo: Hucitec, 1993. p.19-91.

O consenso do discurso e o dissenso da prática social. Notas sobre a municipalização da saúde no Brasil. In: ASSOCIAÇÃO BRASILEIRA DE ENFERMAGEM, COMISSÃO PERMANENTE DE SERVIÇOS DE ENFERMAGEM. Descentralização em saúde e a prática da enfermagem. Brasília: 1992. p.21-7. (mimeogr.).

MENICUCCI, T.M.G. O Sistema Único de Saúde, 20 anos: balanço e perspectivas. Cad. Saude Publica, v.25, n.7, p.1620-5, 2009.

MINAYO, M.C.S. O conceito de representações sociais dentro da sociologia clássica. In: GUARESCHI, P.A.; JOVCHELOVITCH, S. (Orgs.). Textos em representações sociais. 7.ed. Petrópolis: Vozes, 2002. p.89-111.

O desafio do conhecimento: pesquisa qualitativa em saúde. 7.ed. São Paulo: Hucitec, 2000

MOSCOVICl, S. On social representations. In: FORDAS, J.P. (Ed.). Social cognition: perspectives on everyday understanding. London: Academic Press, 1981. p.181 209.

A representação social da psicanálise. Rio de Janeiro: Zahar, 1978.

NARVAI, P.C. Saúde bucal coletiva: caminhos da odontologia sanitária à bucalidade. Rev. Saude Publica, v.40, n.esp., p.141-7, 2006.

NORONHA, A.B.; SOPHIA, D.; MACHADO, K. Formação profissional em Saúde. Radis, n.3, p.11-7, 2002. 
NUNES, M.F. et al. A proposta da Educação Permanente em Saúde na formação de cirurgiões-dentistas em DST/HIV/Aids. Interface - Comunic., Saude, Educ., v.12, n.25, p.413-20, 2008.

OLIVEIRA, F.O.; WERBA, G.C. Representações sociais. In: STREY, M.N. et al. (Orgs.). Psicologia social contemporânea: livro-texto. Petrópolis: Vozes, 2002. p.104-17.

OLIVEIRA, D.C. et al. A política pública de saúde brasileira: representação e memória social de profissionais. Cad. Saude Publica, v.24, n.1, p.197-206, 2008.

PAIM, J.S. Uma análise sobre o processo da reforma sanitária brasileira. Saúde Debate, v.33, n.81, p.27-37, 2009.

Reforma sanitária brasileira: contribuição para a compreensão e crítica. Salvador: EDUFBA, 2008.

. O SUS no ensino médico: retórica ou realidade? In: (Org.). Saúde, política e reforma sanitária. Salvador: Centro de Estudos e Projetos em Saúde/Instituto de Saúde Coletiva, Universidade Federal da Bahia, 2002. p.245-59.

Bases conceituais da reforma sanitária brasileira. In: FLEURY, S. (Org.). Saúde e democracia: a luta do Cebes. São Paulo: Lemos Editorial, 1997. p.11-24.

PATTON, M.Q. Qualitative research \& evaluation methods. 3.ed. London: Sage, 2002.

PUCCA JUNIOR, G.A. Políticas de saúde bucal e a formação de um novo perfil profissional. In: TERADA, R.S.S.; NAKAMA, L. (Orgs.). A implantação das diretrizes curriculares nacionais de odontologia: a experiência de Maringá. São Paulo: Hucitec, 2004. p.149-58.

RONCALLI, A.G. A organização da demanda em serviços públicos de saúde bucal: universalidade, equidade e integralidade em saúde bucal coletiva. 2000. Tese (Doutorado). - Faculdade de Odontologia, Universidade Estadual de São Paulo, Araçatuba. 2000.

SANTOS, N.R. A reforma sanitária e o Sistema Único de Saúde: tendências e desafios após 20 anos. Saúde Debate, v.33, n.81, p.13-26, 2009.

STAKE, R.E. Case studies. In: DENZIN, N.K.; LINCOLN, Y.S. (Eds.). Handbook of qualitative research. London: Sage, 2000. p.435-54.

TERADA, R.S.S.; NAKAMA, L. (Orgs.). A implantação das diretrizes curriculares nacionais de odontologia: a experiência de Maringá. São Paulo: Hucitec, 2004.

TRIVIÑOS, A.N.S. Introdução à pesquisa em ciências sociais: a pesquisa qualitativa em educação. São Paulo: Atlas, 1987. 
CAMARGO, S.X.; NAKAMA, L.; CORDONI JUNIOR, L.El Sistema Único de Salud como paradigma em las representaciones sociales de los cirujanos dentistas. Interface Comunic., Saude, Educ., v.15, n.38, p.883-900, jul./set. 2011.

Este estudio se propone verificar si el Sistema Único de Salud brasileño (SUS) es reconocido por los cirujanos dentistas como paradigma para sus prácticas profesionales. Tratase de una pesquisa cualitativa de las representaciones sociales de estos profesionales. El grupo reunió cirujanos dentistas com actuación en los servicios públicos de Salud en el estado de Paraná, específicamente servidores públicos y profesores universitarios, siendo constituido por tres casos: profesionales del servicio público tradicional de Londrina, profesionales de la Estrategia Salud de la Familia (ESF) de Curitiba y profesores de escuelas de Odontología de Londrina. Los resultados evidenciaron tres posibilidades: desconocimiento del SUS; conocimiento y escepticismo; conocimiento y utopía. Se concluye que el SUS no es plenamente reconocido como referencial para la atención odontológica por los cirujanos dentistas, y que su adhesión al proyecto SUS ocurre solamente en la contingencia de la asociación entre conocimiento del SUS y creencia personal em su viabilidad.

Palabras clave: Sistema Único de Salud. Odontología. Salud de la família. Representaciones sociales. Recursos humanos. 